\title{
REFORMA ILUSTRADA Y PROYECTO SOCIAL. SIMÓN BERGAÑO, REDACTOR Y EDITOR DE LA GAZETA DE GUATEMALA (1801-1807) ${ }^{1}$
} ENLIGHTENED REFORM AND SOCIAL PROJECT. SIMÓN BERGAÑO, AUTHOR AND EDITOR OF LA GAZETA DE GUATEMALA (1801-1807)

\author{
Manuel Hernández González \\ Universidad de La Laguna \\ ORCID: 0000-0002 -6936- 9661
} mvhdez@ull.edu.es

(c) (i) ()

\section{Resumen |}

Este artículo estudia el papel desarrollado por el periodista y literato cántabro Simón Bergaño y Villegas como redactor y editor de La Gazeta de Guatemala entre 1801 y 1807. Aborda, en primer lugar, los antecedentes de la revista relacionados con la Real Sociedad Económica de Guatemala, para centrarse más tarde en la contribución de Bergaño en la etapa en la que la dirigió. Seguidamente, desarrolla su línea editorial y se centra en la introducción de planteamientos ilustrados en todos los órdenes dentro de ella, entre los que destacan su interés por la ciencia, por las condiciones de vida de los indígenas y por la educación de las mujeres. Estudia, a continuación, sus conexiones exteriores y su proyección en Nueva España y en la Península. Se analiza, finalmente, la oposición de los sectores conservadores de la sociedad guatemalteca, entre ellos la del arzobispo de la diócesis, que condujeron, primero, a un intento de limitación de contenidos y, después, a su supresión.

Palabras clave: Prensa en Hispanoamérica; Guatemala; Ilustración; Reformismo borbónico; Ciencia y Pensamiento ilustrado.

\begin{abstract}
This article examines the role played by the Cantabrian journalist and writer Simón Bergaño y Villegas as author and editor of La Gazeta de Guatemala between $180 \mathrm{I}$ and 1807. It first discusses the history of the journal related to the Royal Economic Society of Guatemala, and then focuses on Bergaño's contribution during the period when he directed it. It develops its editorial line and focuses on the introduction of a large variety of enlightened approaches at all levels within it, including its interest in science, the living conditions of indigenous peoples and the education of women. The article also studies its external connections and its projection in New Spain and the Peninsula. Finally, it analyzes the opposition of conservative sectors of Guatemalan society, including that of the archbishop of the diocesis, which led, first, to an attempt to limit content and, later, to its suppression.
\end{abstract}

Keywords: Latin American Press; Guatemala; Enlightenment; Bourbon Reformism; Enlightened Science and Tought.

\footnotetext{
Recibido/Received: |2/10/2021

Aceptado/Accepted: 21/01/2022

Esta investigación se inscribe en el marco del proyecto Identidades en movimiento. Flujos, circulación y transformaciones culturales en el espacio atlántico (siglos XIX y XX). Plan Nacional de I+D+i. Ref.: PID2019-106210GB-100.
} 


\section{| Introducción |}

El objetivo de este artículo es introducirnos en la labor periodística desarrollada por el escritor y literato cántabro Simón Bergaño y Villegas en uno de los periódicos más significativos de la llustración americana, La Gazeta de Guatemala, en la que comenzaría como redactor y terminaría en su etapa final como editor de la mayor parte de la misma. A través del estudio de ese órgano de prensa, de documentación procedente del Archivo General de Indias y de folletos y bibliografía, trataremos de aproximarnos a los planteamientos ideológicos de este rotativo y al papel desarrollado en él por su redactor y editor entre 1801 y 1807. Funcionario de la gobernación, Bergaño proyectaría en La Gazeta sus avanzadas ideas ilustradas y liberales, lo que conduciría a agudos conflictos, primero con el prelado de la diócesis, el cubano Luis Peñalver, que trataría de censurar sus contenidos y su dirección y, más tarde, con el capitán general Antonio González, que finalmente derivaría en el cierre de la revista y, más tarde, en su fulminante expulsión de Guatemala en 1809.

\section{| La etapa anterior: un proyecto de la Real Sociedad Económica de Guatemala |}

El dominicano Jacobo de Villaurrutia, oidor de la Audiencia de Guatemala, fue, junto con el obispo Juan Félix Villegas, el promotor y financiador de La Gazeta de Guatemala desde su arribada en 1794. Aunque nominalmente Villaurrutia era su director, depositó la edición de la revista en Alejandro Ramírez, natural de Alaejos (Valladolid), amigo suyo desde su etapa como corregidor en Alcalá de Henares, educador de sus hijos, y futuro marido de su hermana, que era por entonces funcionario de la Real Hacienda. Ramírez no tenía estudios universitarios, pero despuntaba con una gran formación. Sería más tarde Intendente de Puerto Rico y de Cuba, donde desarrollaría sus proyectos ilustrados. Íntimamente ligada a la Real Sociedad Económica de Amigos del País de Guatemala, aprobada por el monarca en 1795, La Gazeta se convertiría en un certero vehículo de difusión de las ideas ilustradas en la sociedad colonial con proyección en México y en Cuba (Poupeney Hart, 2021, Hernández Pérez, 2015). Sin embargo, la entidad fue disuelta en 1800 por motivos todavía no totalmente clarificados (Lanning, 1956, Luque, 1962). La hostilidad del regente de la Audiencia, Ambrosio Cerdán, a pesar de que había contribuido en su destino anterior a la potenciación del Mercurio peruano desde su puesto como presidente de la sociedad académica de la que ese periódico servía de plataforma, posiblemente se debía a las tensiones existentes en las clases dirigentes guatemaltecas entre los comerciantes partidarios de la continuidad del monopolio, con los que se identificaba el magistrado, y los del comercio de neutrales, posibilitado en 1797 por el capitán general José Domás del Valle, y posteriormente prohibido por orden regia, del que era partidario Villaurrutia (Chandler, 1976), y la máxima autoridad militar, que sería fulminantemente cesada. Aunque el periódico no fue definitivamente clausurado, se ordenó su control 
por dos censores que vigilaban sobre la colocación de noticias fuera de los cauces oficiales y sobre las obras propiamente literarias. Las estrechas relaciones de Ramírez, designado secretario del Consulado, y de su protector con el mayor impulsor de ese tráfico mercantil, el navarro Juan Bautista de Irisarri, se pudo evidenciar con su traslado en sus buques por las Antillas y los Estados Unidos, donde fue designado socio de la American Philosophical Society (Bertrand, 2011).

\section{| La arribada de Simón Bergaño a Guatemala |}

Calificado por el arzobispo de Guatemala, el cubano Luis de Peñalver, como "un joven de origen desconocido"2, Simón Bergaño era sin embargo natural de la localidad cántabra de Potes, procedencia que solo desvelaría en uno de sus numerosos escritos en Cuba y en un folleto de respuesta a la reproducción en el n ${ }^{\circ} 34$ de $L a$ Tertulia de $L a$ Habana de la representación que ese prelado dirigió al Consejo de Estado contra él cuando era editor de La Gazeta de Guatemala. Solo entonces desveló que "la familia de los caballeros Bergaños de Cervera nada tenía que envidiar a la de los Peñalveres”. Aseveró que se llamaba y siempre se había llamado Simón Bergaño y Villegas, que era "castellano viejo, nacido en la villa de Potes, cabecera de la provincia de Liébana, en el Reino de León”. Declaraba a continuación ser "hijo legítimo y de legítimo matrimonio de D. Juan Antonio Bergaño y Villegas y de Doña María de Villegas Fernández de Bulnes, personas de notoria nobleza y solar conocido en las villas de Potes y Cervera del Río Alhama". Refrendó que se había criado y había estudiado en Asturias y que había sido llamado a Cádiz por su tío Pedro Fernández de Bulnes, quien le había conseguido carta-orden para colocarle en el colegio de guardias marinas. La muerte de su progenitor y el haber reñido con su tío le hizo mudar de parecer y le llevó a embarcarse con real permiso para América. Arribó a Veracruz en diciembre de 1799 y dos meses después a Guatemala. Perdió la protección del prelado de la diócesis, su lejano pariente Juan Félix de Villegas, fallecido el 3 de febrero de 1800, poco tiempo antes de su llegada, sin que este pudiese hacerle "el bien" que le "había prometido". Al verse desamparado, pensó dirigirse a La Habana, donde le esperaba con "los brazos abiertos" el comerciante Enrique Eusebio de Amorrostra, amigo y corresponsal de su tío, "en atención (son palabras de mis despachos) de mi acreditada aptitud y notorias buenas circunstancias". Sin embargo, decidió quedarse en esa ciudad, al conferírsele una plaza en la secretaría de cámara del gobierno, presidencia y capitanía general. En esa urbe permaneció por espacio de ocho años, hasta que "unas circunstancias puramente locales, me obligaron a salir de alli’” (Bergaño, 1812, p.3)3. El pasaporte con el que ingresó en Guatemala avalaba, no obstante, que se llamaba también Simón Carreño. Con ese nombre se titularía en sus primeros artículos en La Gazeta de Guatemala, para modificarlo más tarde por el de Simón Bergaño y Villegas. En las

2 Archivo General de Indias (A.G.I.). Guatemala, 649.

${ }^{3}$ Archivo Histórico Nacional de Madrid (A.H.N.). Consejos, leg. 21035.

SHJ, 2022, 2(I), pp. 87-104. ISSN: 2792-3967

89 
fechas aproximadas en las que nació, en torno a 1780-1781, no aparece ningún niño bautizado con alguna de esas dos denominaciones ${ }^{4}$.

\section{| La incorporación de Bergaño a la redacción |}

La ausencia de Alejandro Ramírez en las expediciones entre 1799 y 1801 y su nombramiento como secretario de la gobernación en 1802 llevaron a que la redacción de la revista fuera encargada a un consejo controlado por dos censores, en el que se introdujo desde 1801 el cántabro Simón Bergaño y Villegas, cuya participación en el semanario fue creciente desde esas fechas hasta que en 1804 se convertirá en su editor, cargo que desempeñó hasta su cierre en junio de 1807. En el número 221, de 7 de septiembre de 1801, se reseñó lo que había supuesto de dificultades para la revista la ausencia del vallisoletano por espacio de dos años. Su retorno le llevó, como quedó reflejado en ese número, a encargarse de la clasificación de las materias y de la ortografía. Su marcha proporcionó un gran protagonismo en La Gazeta al joven redactor Simón Bergaño, destinado como oficial de la secretaría de Gobierno y con una misión muy precisa en ella: la recopilación de las Reales Órdenes. Esa función se conectó directamente con su trabajo en el semanario. En él, a medida que pasaba el tiempo, fue ganando protagonismo con la introducción paulatina de sus planteamientos ideológicos y sus puntos de vista, aunque sin alcanzar el papel de editor que detentará entre 1804 y 1807 , en el que prácticamente será revestido como su único redactor. Un consejo de redacción y una junta de censura, de la que no aparecen sus nombres, tratará de controlar los contenidos no estrictamente gubernamentales. Durante esos tres primeros años predominarán dentro de La Gazeta las noticias oficiales e informaciones de carácter científico, aunque los postulados ilustrados ocuparán un papel cada vez más crucial.

La huella de Bergamo en La Gazeta de Guatemala se puede apreciar inequívocamente en el prólogo al tomo $\mathrm{V}$, de 2 de marzo de 1801. En él, de forma irónica, aseveraba que se acomodaba con sus vestidos modestos a las facultades, opiniones y costumbres del país, por ser "nuestra muchacha y la alindaremos como mejor nos parezca", dotada de "padres y tutores a quienes obedecer, agradar y dar pruebas de subordinación". Manifestó que vivía "obediente a sus directores", con los que se granjeaba un apoyo seguro y durable". Estos le permitían "ciertos desahogos y diversiones, que no desdicen de lo justo ni se oponen a las leyes del pudor y de la buena crianza". A tales cortejos se mostraba esquiva, ya que se deslizaba y escapaba de las manos por donde menos se pensaba. Especificaba que no sabía a donde iban a parar tales requiebros, pero recomendaba que debían dejarla "entre tanto caminar a su salvo"5. Mostraba con todo ello su afán de lidiar con la censura de su junta de calificadores.

\footnotetext{
${ }^{4}$ Archivo Catedralicio y Diocesano de Santander. Libro de bautismos de Potes de 1 de agosto de 1778 a 25 de julio de 1782. Todas las citas de La Gazeta de Guatemala de este artículo están tomadas de la edición digitalizada que se encuentra en Poupeney Hart, C. (2021).
} 
En el número 197, de 30 de marzo de 1801, aprovechó una reseña del Seminario de Agricultura madrileño de 1 de noviembre de 1798 sobre la obra pía de la marquesa de Cerralbo para dotes de cien ducados anuales otorgadas de forma vitalicia entre los labradores de sus pueblos para criticar con contundencia que se dejasen gruesos caudales en mayorazgos "para sostener una familia devoradora y destruidora" y para dejar sus réditos "a la ociosidad y los vicios de unos cuantos". Se preguntaba por el hecho de que, si las propiedades eran "un resultado del bien público", su distribución, "para ser meritoria, debe ser justa". Solo la virtud tendría que reclamarla, por lo que lamentaba que no hubiera en Guatemala personas revestidas de ella, ya que "no se verían tantos monumentos de ruinas, despoblación y miseria en un país tan bello y bajo un cielo tan alegre".

Esa dimensión crítica de la sociedad guatemalteca tomó viva expresión en una serie de artículos dados a la luz a partir del número 232 de 15 de octubre de 1801, dedicados a la condición de los indios. En ellos se muestra contrario a la acusación de estos como ociosos. No creía que "esa miseria provenga de que no quieren aplicarse a trabajar". Frente a esa concepción, refrendó que Guatemala en toda su extensión "no produce fruto alguno que no se deba al esfuerzo de sus brazos". Los hacendados no hacían otra cosa que "estarse quietos hasta verificar sus cosechas y recoger en limpio sus frutos". Se encontraba algún español, mestizo, mulato o negro que labrase la tierra, "pero son estos tan raros que entre todos no componen una milésima parte". Sobre su laboriosidad, en el número 234 , de 22 de octubre, reseñó que eran los únicos que levantaban los templos, casas, jardines, muros y todo género de mampostería. Por ello, "el único, seguro y general recurso de este Reino se encuentra fundado" en su trabajo infatigable. Sin embargo, se insistía en que eran ociosos y que, para mejorarlos, debían vestir y calzar. Expresa que no se les daba otra salida, que eran "unos borrachos y que por este vicio pierden mucho tiempo". No se cargaba contra las restantes castas, en las que "se palpa la holgazanería y la desidia". Para él, los verdaderos ociosos eran los que se empleaban en la búsqueda de arbitrios para que estos trabajasen. Continuó reflejando tales críticas en el número 236 , de 29 de octubre. Insiste en que eran los verdaderos bienhechores, ya que "sin nuestros labradores, ni con el trabajo, sin él era posible vivir". Aludiendo a Adam Smith, afirmó que por esa constancia deberían ser muy ricos. Mas, siendo los que trabajan sus tierras y los operarios de las ajenas, pese a ello "porqué, si los jornaleros no ganan para vivir, su raza no podrá pasar de la primera generación". Eran los individuos que menos gastaban en personas y que a menor costa satisfacían sus necesidades, "enemigos de todo lujo y profusión, están limitados a lo indispensable necesario para subsistir sus vidas". Refrendaba su argumento otro escrito del número 237, de 2 de noviembre. En él describía las duras condiciones de vida de los indígenas como campesinos, trajinantes y mineros, para concluir que en todos sus oficios "no puede juntar nada seguro para su posteridad", por lo que "con el corazón enternecido", pese a todo su encomio, los llaman "holgazanes, ociosos, degenerados e imbéciles."

La crítica a las supersticiones fue uno de los ejes centrales. En el número 235 , de 26 de octubre de 1801, se hizo eco de una denuncia efectuada ante la Audiencia de SHJ, 2022, 2(I), pp. 87-104. ISSN: 2792-3967 
Guatemala contra unos indígenas por parte de otros de su mismo pueblo. Eran acusados de tener potestad superior para atraer lluvias o repelerlas. Fueron sentenciados a ser privados de sus honores y cargos de justicia, condenados a cincuenta azotes y obligados a aprender la doctrina cristiana. En su discurso, recogió que no se trataba de algo exclusivo de los indios, sino que revestía "carácter de un accidente universal, de que todos los hombres adolecen $\circ$ a que todos tienen tendencia o inclinación", que se combatía con la acción de las luces. En el número 239, de 2 de noviembre de 1801, y en el 240, del 14 de ese mes y año, firmado por un supuesto licenciado Mateo Zorrilla desde México, que es en realidad él mismo, por haberse conservado en su archivo tales ideas, el artículo "Monjíos" arremete contra las profesiones de las monjas que residían en la conveniencia de las familias y que eran mucho más lujosas y poco rigurosas que las de los frailes. En el número 240, de 14 de noviembre de 1801, dio a la luz anónimamente su primer poema "Antipatía entre las musas y los negocios. A Albano". Lo hizo proceder de un cuaderno manuscrito y lo denominó “lánguida composición”.

El tomo $\mathrm{VI}$ se abre en su número 241 el 11 de enero de 1802 de forma irónica con "una advertencia general para este tomo y siguientes: Los editores no saben hacer prólogos", en contraste con el amplio prefacio del anterior. En una serie de artículo denominados "Necesidades facticias", en el número 243 se preguntaba qué había que hacer para que los indios fueran más trabajadores y mejores vasallos y responde que "darles nuestras necesidades, acercarlos cuanto sea posible a nuestros goces, en una palabra, hacerlos todo lo que nosotros somos, aplicando, en cuanto lo permiten las circunstancias, los mismos medios porque nosotros lo hemos venido a ser". En el 245, de 6 de febrero de 1802, Bergaño insiste en un tema en el que sigue a Campomanes, que tenía en su biblioteca. En "Educación popular" sostiene que la línea entre la educación sabia y la popular ha solido confundirse en detrimento de una y de otra. El labrador, aunque no supiese del sistema planetario para dar razón de un eclipse, si "es religioso, prudente, valeroso, activo, útil a la sociedad en el lugar que le ha cabido en ella, tiene toda la instrucción, todo el cultivo conveniente”. El 1 de marzo de 1802, en el número 248, vuelve al tema del trabajo de los indios al criticar los prejuicios sobre ellos al considerarlos ociosos. Frente a esa acusación sin fundamento responde con contundencia que era falsa porque los parásitos florecen a costa de su jugo. Expone el tributo percibido por la Corona, "los curas, coadjutores, familiares, caballos, mulas \&, todos comen y beben a cuenta de los indios", las primicias, bulas, recibimiento de visitadores y pasajeros de distinción e incluso los alcaldes mayores que "se hacen ricos en pocos años y tienen agregados y dependientes que también comen, visten y gastan sin renta conocida, a los que les siguen los delegados, medidores de tierras, contadores, maestros de escuela". Todos ellos viven de su trabajo.

En el número 252, de 29 de marzo de 1802, se manifestó sobre literatura afirmando sus lecturas del Telémaco de Fenelon, que poseía en su biblioteca. Expresaba que con estos mentores habían de ser escasos en España y por ende "lentos los progresos que hagan las letras en España”. A pesar del gran número de obras dadas a la luz, era muy rara la que lograba fama póstuma. Lo atribuía a la falta de profesores en la república 
literaria, por lo que se malograba el verdor de sus años en la lectura infructuosa. En su artículo "Estudios" del número 254, de 12 de abril del mismo año, insistía en que la enseñanza de las ciencias no debía impartirse en lenguas extranjeras, apartadas del uso común y trato de las gentes. En ese mismo número incide en que era raro el discípulo que aventajaba al maestro, por lo que por eso no se producía el necesario avance de las ciencias y las letras. El número 257, de 3 de mayo, abogaba por los planteamientos de Rollin de preferir la explicación de los autores a la práctica de la composición, por ser para los estudiantes un trabajo penoso y de poca utilidad. En el número 261, de 31 de mayo, defendió que los cursos debían estar purgados de "quimeras escolásticas y enriquecidos con todos los conocimientos de la historia natural, de la mecánica, de las artes útiles, de las costumbres y de las leyes". Sostuvo que las conclusiones debían eliminarse por ser opuestas a los principios de la llustración, siendo los exámenes razonados más ventajosos. A partir del número 262 , en una serie sucesiva de artículos denominados "Lengua para todos", hizo suyos los principios de la pasigrafía, que denomina escritura para todos, con la que cada nación mantenía su propio lenguaje y con facilidad podía entender la de la otra. Arguyó que Wilkins, Dalgarme y, más tarde, Leibniz, profundizaron en un lenguaje filosófico que para que fuera universal demandaba signos fáciles y explicados con suma claridad. En opinión del último deberían parecerse a los del álgebra. En el número 273, de 23 de agosto de 1802, y en el siguiente, de 30 de ese mes, resalta la publicación de una Biblioteca española económico-política que, desde Guatemala, había echado de menos, aunque pensaba que debía proyectarse en un plan más extenso.

El 30 de agosto de 1802, en su número 274 , dio comienzo a una serie de artículos titulados "De la limosna", que más tarde serían denunciados por el prelado Peñalver. Abogaba en ellos que no se concediesen las dádivas que no excitasen las ganas de trabajar, por ser opuestas a la felicidad temporal y espiritual de la patria. En consecuencia, aseveró que, si no se promovía la industria popular en nuestros dominios, se fomentaría de contado los extranjeros, por ser "el alma que vivifica el cuerpo de un Estado". Reflejó que las limosnas ordinarias "radican en nuestra nación la más dolorosa holgazanería", por no servir más que para paliar las necesidades extrínsecas y suministrar pábulo "a las intrínsecas, que son verdaderamente las más devoradoras de la felicidad pública”. Propugnaba la creación de juntas provinciales que ordenasen el método uniforme con que se debían socorrer las necesidades de los pueblos. Para él, "las limosnas ordinarias radican en nuestra nación la más dolorosa holgazanería".

La publicación de textos de interés etnográfico y naturalista es una de las preocupaciones plasmadas en La Gazeta, en la que se aprecia sus estrechas conexiones con los científicos más significativos de su tiempo. En una serie de artículos reproducidos en sucesivos números de la revista, se publicaron las Noticias de Nutka del mejicano José Rodríguez Moziño, botánico de la Real expedición de la Nueva España y Guatemala y de la de límites al norte de California. En una nota del número 320, de 12 de septiembre de 1803, se declaró "amigo cordialísimo del autor y amante de la patria”. Creía muy útil esa narración. Expresó que la habría dado a la luz con SHJ, 2022, 2(I), pp. 87-104. ISSN: 2792-3967 
anterioridad comparándolo con el diario de Vancouver, que llevaba cinco años editado en Londres. Sin embargo, se lamentaba de que no fuera trasladado al español, lo que le llevó a ironizar que en España "se traducen novelas, que son sin duda mucho más útiles". El número 373, de 21 de enero de 1804, estuvo dedicado a la memoria del director del Real Botánico de Madrid Antonio José Cavanilles. Destacó que "cuando España hacía un papel tan humilde, en muchas partes injusto, Cavanilles empezó a florecer y trabajó con tesón por la gloria de su patria y de las ciencias". Elogió al nuevo director de ese centro, el novogranadino Francisco Antonio Zea, "discípulo del célebre Mutis, que en su primera intervención exhortó la difusión de las ideas útiles y su aplicación ventajosa", por lo que ansiaba que "el cumplimiento de tan bellas promesas" fuera "el monumento que puede levantarse a la memoria" de su predecesor. Esperaba que saliesen a la luz los trabajos sobre Guatemala de Sessé y Moniño, ya que, hasta el día, "el Reino de Guatemala todavía no ocupa ni una página en la historia de las ciencias naturales". A partir de su número 400, de 26 de agosto de 1805, se recogió un extracto del viaje a las regiones equinocciales del Nuevo Mundo de Alejandro de Humboldt a través de la traducción de la noticia recogida por J. C. Delemetherie.

El número 397, de 3 de agosto de 1805, está dedicado al catedrático de medicina de la universidad de San Carlos de Guatemala José Antonio de Córdoba, que acababa de fallecer. En "Al mérito" expresaba que a él se debía el estado brillante de la medicina en Guatemala, en el que le secundaban el doctor Flores y Narciso Esparragosa, el artífice del Colegio de Cirugía. Explicitaba que todos ellos trataron de ilustrarse por sí mismos, pues no contaron con maestros hábiles, por lo que se aplicaron al estudio de la lengua francesa, "conociendo que estaban manifiestos en ella los mejores y más sazonados frutos de las ciencias y se adornaron con una instrucción tan selecta". Afirmaba que "tanto en América como en Europa es bien conocida la habilidad del doctor Flores como médico honorario de cámara, que de orden y expensas de S.M. salió hace años de esta capital para rectificar y adelantar sus conocimientos físicos".

Bergaño se interesó por la educación de las mujeres. En un texto con esa denominación impreso en el número 333 de 12 de diciembre de 1803 aludía a que la sensibilidad femenina y la viveza de sus pasiones las capacitaban con una disposición universal para todo tipo de conocimientos. Defendía que si estas virtudes se cultivasen con más cuidado "serían la felicidad de ambos sexos y de la sociedad, con el cultivo del entendimiento literario de conciencia". En él expresaba que él era el portavoz del reino para las cosas literarias. Al abrir sus baúles se encontró con las obras de Massillon, la Lógica de Condillac, El viajero universal, Bayle, el Telémaco de Fenelon, el Mélange amusant de saillies d'esprit de Lesage, o las Memorias políticas de Larruga, de cuyo tomo $\mathrm{V}$ no dudó en afirmar que habían resultado más importantes para la humanidad que "todas las disputas y cavilaciones de los escolásticos". Hoy sabemos que se refiere con "el baúl del joven" a sí mismo, por albergar esas obras en su biblioteca. Esa discusión le permite redactar varias respuestas al Engañado a partir del número 347, de 21 de mayo de 1804, firmadas con el anterior pseudónimo. En ellas profundiza en su crítica al peripato y propugna el desarrollo de la ciencia sin limitaciones, huyendo de "las invenciones aéreas, ridículas y fastidiosas en que se 
ofrecen unas conclusiones que dan muy poco honor a las Universidades", por lo que avala la validez de las ciencias para que "los hombres salgan de la ignorancia que antes los cubría".

A medida que avanza La Gazeta crece el número de poemas de Bergaño, que le sirven para ironizar sobre la sociedad guatemalteca y su minoría criolla. En el número 349, de 4 de junio de 1804, sus versos "El Poeta y el Loro" le permiten denunciar a través de un indio, que se lo había regalado, "a los escritores de aquesta laya que solo repiten lo que otros hablan”. En el 354, de 9 de julio de 1804, se felicita por la proyección del periódico en la Península. Recoge los elogios vertidos por El Regañón general madrileño en su número 3, de 8 de junio de 1803. En él dice que la Gazeta literaria tenía un gran mérito y demostraba "hallarse la literatura en auge en aquel país".

La Gazeta persistió en su afán por difundir una visión más científica y racionalista de la educación en la que no se discriminase a las castas llamadas inferiores. Bergaño en un poema dedicado a Aristóteles en el número 373, de 19 de noviembre de 1804, arremetió contra los escolásticos que habían colocado en sus escritos "sus opiniones, adulterando las del filósofo". Ironiza en sus versos, al no oír desde el infierno:

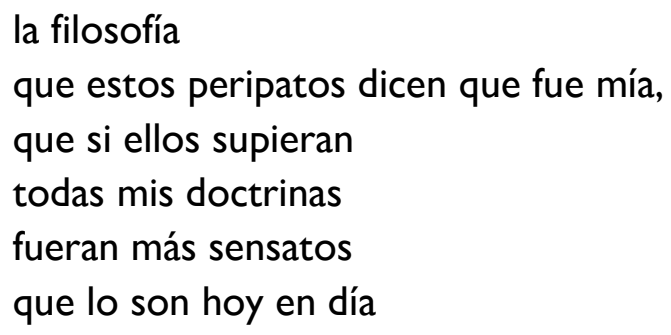

Los versos de Bergaño eran cada día más irónicos y punzantes y a través de ellos satirizaba la realidad cotidiana, lo que sin duda originaba ampollas en las personas que criticaba en clave, como se puede apreciar en este epigrama:

El beato Crispín así decía

En cierta ocurrencia el otro día

Pascual de su talento ha dado prueba

Pero vive con Gila amancebado

Es ratero, tahúr, borracho y lleva

Diez años de no haberse confesado.

Su lengua es de serpiente,

Es mordaz, venenosa y maldiciente,

No hay crédito que de ella esté seguro

¡Qué lástima de hombre! Yo le juro

Que en caso de ser juez no murmurará

Pues su lengua maldita le arrancará

No le falta razón, según parece

Mas la suya, señores, ¿Qué merece? 
Dentro de su campaña genuinamente ilustrada, Bergaño exalta a Buffon. En "De los libros clásicos y sus traducciones”, en el número 380 de 11 de febrero de 1805, tras criticar las añejas traducciones de religiosos, que califica de "malísimas", apuesta por la traducción de libros extranjeros con ideas útiles a la juventud, tanto en francés e italiano, como en inglés o alemán. Exceptúa "el inmenso fárrago de novela" que inunda al mundo, que hacía más daño que los libros de caballería y que demandaba un Cervantes para que desaparecieran de la faz de la tierra, pues la inclinación a su lectura se había apoderado de las mentes débiles.

En el número 391, de 10 de junio de 1805, en un poema denominado "Anacreóntica de mi filosofía", firmado con el pseudónimo de Seciviblas, ya se manifiesta abiertamente como Simón Bergaño, al afirmar:
Dícenme los amigos
¡Qué mal, Simón, parecen
Las quejas en un hombre
De ciencia, que tú eres!
Si ahora porque cuentas
De cama siete meses
Publicas tus dolores
Dicen, Simón, amigo
Dinos, ¿A dónde tienes
La gran filosofía
¿Que enseñan tus papeles?
¡Ah, calla y disimula,
Que el sabio nunca debe
Por pobre o por enfermo
Quejarse de su suerte.

Bergaño siguió en su línea de posibilitar una mayor libertad y educación a la mujer, puntos de vista que más adelante desarrollará en su Correo de las Damas habanero. En el número 398, de 10 de agosto de 1805, en una supuesta respuesta a una hija de familia, que se declaraba como "una de aquellas desventuradas hijas de familia que son, a pesar suyo, mártires de la castidad, o sea virginidad física, según leí en un libro que tenía mi hermano encima de la mesa" (se trataba del tomo IV de Buffon, según él refiere en una nota). La desdichada atribuía sus desgracias a la oposición de su padre a su casamiento con un joven virtuoso, pero pobre, que la amenazó con "la espantosa eternidad de un claustro". Ello llevó a decir al cántabro que "cuántas hay en ellos cuyas vocaciones fueron inspiradas en estos o semejantes términos". Al someterse al arbitrio del confesor, este le subrayó que debía sacrificar su voluntad a la de su padre. Su respuesta era lógicamente "revolucionaria", si el joven era verdaderamente virtuoso y trabajador, debía contraer nupcias con él "a pesar del mundo entero", ya que descendía de Adán y Eva, lo mismo que su padre, por lo que tuviera o no ejecutorias, "más vale tener la nobleza en el corazón, que no en unos pedazos de papel”, ya que "la verdadera riqueza y felicidad del matrimonio consiste en el mutuo amor de los 
contrayentes". Sorprende la libertad con que habla de esas materias en un órgano oficial, a pesar de que la política ilustrada de la Pragmática Sanción de 1776 prescribe la superioridad de la autocracia paterna sobre el libre albedrío de los hijos.

Los problemas bélicos originaron un encarecimiento del papel a raíz de la declaración de guerra a Inglaterra. En el número 399, de 17 de agosto de 1805, se lamentaba de que La Gazeta se daba a la luz "tan diminuta" a causa de la carestía del papel, que originó que la resma pasase de 5 a 7 pesos antes del rompimiento y que en apenas 24 horas subiese hasta los 14. Esperaba que una vez que se abaratase de nuevo volvería a sus anteriores dimensiones. Para conmutar ese perjuicio a los suscriptores se ofrecía a publicar algunos suplementos gratuitos. En ese mismo ejemplar quería impulsar la edición en un folleto del "Canto a la Vacuna", que denomina Poema épico y su "Discurso de Economía Política”. No se expresó en ningún lugar su autoría. Solo se reseña que saldría al frente de ella cuando fuera editada. Se afirma que su propósito era que estaban consideradas como dignas de publicarse por parte de "personas instruidas e imparciales que las han leído confidencialmente". Sin embargo, tales suscripciones no alcanzaron el número suficiente para esa finalidad, que solo pudo ver realizada Bergaño en 1808 gracias al patrocinio del comerciante Roberto Socasa ${ }^{6}$.

Por primera vez, el número extraordinario 406-407, de 23 de septiembre de 1805, se abre con una oda suya dedicada al "infame apresamiento de las cuatro fragatas españolas”, en el que firma con su nombre oficial de Simón Bergaño y Villegas. Se trata de un extenso poema de más de ocho páginas que prácticamente cubre la casi totalidad de la revista. A partir de esa fecha, y hasta la desaparición de La Gazeta en 1807, la relación de versos del cántabro es profusa en casi todos los ejemplares. En el número 408, de 30 de septiembre de ese año, da a la luz "Oda anacreóntica. De los avaros", que le sirve para criticar la mezquindad del dinero al tiempo que a exaltar el hedonismo. Sin duda, tal vocación en una publicación oficial le ocasionó serios problemas. De esa forma finaliza esta obra:

¿Qué piensan tú que haremos?

Divertirnos, holgarnos,

Que en esta vida triste

No encuentro yo, no encuentro

Placeres más amables

Que los de Baco y Venus.

Con el pseudónimo de Bañoger de Sagelliu, en el número 412, de 18 de noviembre de 1805, se puede apreciar la libertad con que se expresa Bergaño con contenidos cada vez más sarcásticos. En él, en su calidad de secretario del "Banco nacional del abuso y tonteras humanas", repartió una serie de premios, entre los que se encontraba el de plomo de diez arrobas, concedido al que redactase una disertación sobre las utilidades físicas y morales en favor de Júpiter y del Estado "con que se queden sin casar muchos

${ }^{6}$ Ha sido reeditada modernamente con prólogo de Cesar Brañas en 2008. 
jóvenes de ambos sexos, a pesar suyo, ya sea por falta de ejecutorias o de talegas en una de las dos partes". Propulsa con ello una batalla por la libertad de decidir por parte de las parejas frente a la autocracia paterna.

A partir del número 413, de 21 de noviembre de 1805, da curso a una serie de artículos bajo el título de "Industria". firmados por él como S. B. y V. En ellos denuncia que "la mayor parte de la América septentrional no tiene una legua geográfica de terreno árido". Guatemala, "teniendo proporciones para aventajarse a todos en la opulencia, es justamente, si no el más infeliz, al menos el más pobre". Afirma que "los robos nacen de la pobreza que ha llegado a oprimir a las gentes educadas sin principios de honor". Proviene de no haber agricultura, fábricas, comercio, "navegación, ni otra cosa que valga". Denuncia el desigual reparto de la tierra, "pues para un hombre que tiene 25 leguas de terreno, y de estas las 24 sin cultivo, hay cincuenta que no tienen un palmo de tierra para sembrar una cebolla". Por ello "la ociosidad es madre de todos los vicios, y la pobreza el agente o muelle para los ladrones”. Mientras que no se les proporcione una subsistencia digna, incomodarán a los vecinos y perecerán en cárceles y destierros. Por ello promueve que "cuerpos patrióticos" impulsen la agricultura y el comercio con el incentivo del premio y del honor. Revisten interés sus apreciaciones sobre los prejuicios hacia los pardos por parte de los que "se precian de españoles, se habla sin perjuicio de las excepciones que tiene toda regla general, ", que los tratan "a la baqueta", por lo que "estos se exasperan, y en vista de que los poderosos les quitan todos los recursos en que pudieran utilizar, se entregan al robo y todo género de maldades". Es una crítica al afán de los llamados blancos de restringir con prejuicios sociales el acceso al poder y la riqueza a los mestizos. Llega a decir que "con los pobres y vagabundos que pueblan y escandalizan las calles de Guatemala, había para fundar un par de colonias numerosas en cualesquiera de las dos costas de Norte o Sur". Expresa que en ambas había "sujetos que poseen haciendas de ocho, quince y hasta de treinta leguas sin otro interés que la tonta vanidad de tenerlas por suyas, con notable perjuicio del bien público". Critica los males del latifundismo y la ignorancia de los hacendados, a los que dice que debían abandonar "las añejas y perniciosas preocupaciones que os ocultan los deberes de ciudadanos y nuestros verdaderos intereses" y les invoca que se dignasen "escuchar las lecciones que 'pienso daros de moral y economía rústica". Estima que "la ciencia rural, tan útil como desconocida en América y en varias partes de Europa, y harto más importante y digna de atención que toda la ciencia escolástica" está empeñado en darla a conocer, aunque lamentaba no poder presentarles una obra "tan acabada como el Almanak rústico del pobre Ricardo publicado en Filadelfia por "el sabio Franklin", por no tener inteligencia en su idioma "para aprender de él", aunque manifestaba que se esforzaría en cuanto le alcanzasen sus débiles talentos, ya que "las máximas rurales de aquel gran hombre pasaron a proverbios entre los angloamericanos, según me ha dicho un amigo”.

A medida que avanza cronológicamente la revista, aumenta el protagonismo de Bergaño dentro de ella. En el número 415 da a luz con su firma una "Oda anacreóntica. La partida”. En el 417, de 23 de diciembre de 1805, destapa uno de los campos de estudio en el que seguirá profundizando más tarde en La Habana. Se trata del sistema 
craneognómico del médico alemán Gall. Con esos principios refleja que ese galeno compara los cráneos de los animales con los de los hombres, "parecidos en parte, aunque muy diferentes en cuanto a sus facultades". Se trata de uno de los trabajos pioneros sobre el considerado padre de la frenología, anterior en un año a la primera obra impresa en España (García González, 2013, pp. 13-29). Este sistema considera al cerebro como un conjunto de órganos. A cada uno de ellos le corresponde una facultad intelectual, instinto, afecto y cualidad moral. En este caso, Bergaño se fundamenta en una traducción francesa, lo que es indicativo del nivel de conocimiento alcanzado por el cántabro, a pesar de las dificultades de comunicación reinantes. En ese mismo ejemplar recoge su poema "Idilio a Tirsi".

\section{| La ofensiva del prelado Peñalver contra la Gazeta |}

El 8 de enero de 1806, el arzobispo de la diócesis guatemalteca, el habanero Luis Peñalver, denunció La Gazeta de Guatemala ante el Consejo de Indias. Aludía al hecho de que "su redactor suele insertar papeles teológicos, algunos sobre historia sagrada, otros contra la enseñanza de la lengua latina, sin perdonar los usos generalmente recibidos en todas las catedrales y a veces satirizando a personas determinadas". Sin embargo, lo que más había excitado su celo eran los contenidos de seis números, que avivaban "las pasiones de la carne, anticipan a la juventud los conocimientos que debía ignorar e incitan la lascivia con versos amatorios y no falta papel en que se ofende la justicia y la piedad con santo temor de Dios". Sostiene que la argumentación del capitán general de cometer el examen del periódico a dos sujetos bajo la dirección del juez de imprenta no había sido efectiva por abordarla superficialmente. Arremetió contra su redactor, del que dijo era "joven de origen desconocido, pero lleno de amor propio y no de buenos pensamientos". No era su ánimo prohibirla, como se había efectuado con la Sociedad, pero sí planteaba que debía ceñirse a "asuntos generales de policía, descubrimientos útiles, comercio, agricultura, providencias de gobierno y otros fines de su institución, sin avanzar a los particulares referidos". Asimismo, solicitaba que no se diese a la prensa papel alguno sin revisión previa del prelado, ya que debiendo él responder a Dios por sus ovejas, "velará para que no se difunda la mala semilla"8.

Los argumentos esgrimidos por el arzobispo se ceñían a seis números de ese rotativo. El primero, fechado el 4 de julio de 1803, se refería al informe del cirujano venezolano asentado en Guatemala Narciso Esparragosa sobre los hermafroditas, que entendía no debía haber publicado, por suministrar "a la juventud nociones impuras" y provocar "a la lascivia”. El segundo, de 7 de mayo de 1805, versaba sobre un epigrama de Bergaño dedicado a su amada Helena, que calificó de "cuarteta obscena". Había sido suscrita por el poeta con el sobrenombre de Sapelliu, anagrama de Villegas, su último apellido. Las otras cuatro contenían expresiones de ese carácter, como el de una "oda

${ }^{7}$ A.G.I. Guatemala, 649.
${ }^{8}$ A.G.I. Guatemala, 649.

SHJ, 2022, 2(I), pp. 87-104. ISSN: 2792-3967 
anacreóntica de los avaros", cuyos últimos versos exhortaban a los placeres mundanos, que fue dada a la luz en el número 409 de 7 de octubre de 1805:

¿Qué piensas tú que hacemos?

Divertirnos, holgarnos

Que en esta vida triste

No encuentro yo, no encuentro

Placeres más amables

Que los de Baco y Venus. ${ }^{9}$

Los tres restantes poemas debidos a la pluma de Simón Bergaño y Villegas se corresponden con los números 387, de 14 de mayo de 1805, 415, de 2 de diciembre de 1805 y 419, de 6 de enero de 1806. El primero se denomina "Letrilla". En ella, entre otros asertos, criticaba la visión del infierno como lugar de

Sapos,

Culebras y gusarapos,

Garfios de hierro encendido

Y a más plomo derretido

Con azufre cual poleas

No lo creas.

Critica también el modelo familiar cimentado en el mayorazgo:

Que desde su juventud

Fabio el hermano galán

De un mayorazgo holgazán

Busque por pura virtud

En el claustro su quietud

Despreciando las libreas

No lo creas.

Fue calificada por el arzobispo como:

versos satíricos que parecen burla de la rectitud de los tribunales, de la conversión de los jóvenes ricos y nobles, de la penitencia corporal, de las congregaciones piadosas y de las ideas que ordinariamente hace uso el pecador para meditar las penas del infierno y entrar en el temor de los juicios de Dios ${ }^{10}$.

La segunda composición era la oda anacreóntica "La Partida". Fue calificada por el arzobispo como indicada "para despertar las pasiones más desordenadas y vergonzosas". En la tercera, denominada "Epigrama", se expresaba que

Andrés me llegó a coger

Anoche dando las dos

A solas con su mujer 


\section{Guiñó el ojo, dio una tos \\ $Y$ dijo: tengo que hacer \\ Quédense ustedes con Dios.}

Fue descrita por Luis Peñalver como "patética pintura de un marido consentidor", por lo que era "mal proemio para hablar seguidamente de la oratoria sagrada y un incentivo a la desenvoltura e infidelidad del matrimonio"11.

El fiscal del Consejo de Indias expuso el 22 de julio de 1806 que, si bien eran dignos de crítica algunos contenidos de la revista, en otros se encontraban versos similares a los aprobados en rotativos semejantes y descripciones como las del cirujano Esparragosa sobre los hermafroditas, por lo que no había motivo para prohibirla por contener "especies útiles y bien escritas". Aseveraba que creía, como el arzobispo, que debía limitarse su contenido a lo apuntado por él, pero consideraba que este prelado se había extralimitado al entrometerse en lo que era "privativo de la jurisdicción real", ya que solo debía intervenir la jurisdicción eclesiástica en las exhortaciones a sus ovejas para "apartarlas de los desaciertos en que puedan incurrir con semejantes incentivos"12.

La decisión final del Consejo de Indias de 21 de julio de 1806 recoge que, "sin necesidad de que el ordinario eclesiástico revise tales papeles", se ordena al Presidente que hiciese saber al juez de imprentas la obligación de no permitir que la inserción en La Gazeta de textos que desdigan "la buena moral y política o que pueda excitar las pasiones, quedando responsable de la menor falta que se note en este punto". Refrenda que le transmitiese al juez de imprentas que a este organismo le había parecido muy mal la inserción del informe médico sobre hermafroditas, ya que, "aunque se haya extendido con cuanta decencia permite su naturaleza", no era apropiado para una revista que no estaba destinada a facultativos y en la que convenía su recepción de tales materias por quienes no lo eran"13.

En su ya citada Vindicación habanera, Bergaño dejó constancia de que las quejas iniciales de Peñalver al Gobierno de Guatemala fueron respondidas por este con que "no había nada digno de censura", por ser este "uno de los más sabios que en aquella época había en toda América". Ante su fracaso, recurrió al ministro de Estado, creyendo conseguir un triunfo como el obtenido contra el Periódico de La Habana en 1793. Pero devino en "una friolera: S.M no ha encontrado en las especies que V.S. llustrísima acompaña con su carta especies dignas de su real desagrado" (Bergaño, 1812, p. 2).

\footnotetext{
${ }^{11}$ A.G.I. Guatemala, 649

${ }^{12}$ A.G.I. Guatemala, 649 .

${ }^{13}$ A.G.I. Guatemala, 649.
} 


\section{| La última etapa del rotativo |}

En el número 424, de 17 de febrero de 1806, comienza un "diccionario de árboles, plantas y hierbas de la provincia de Verapaz por orden alfabético, sus usos, utilidades, etc”. Reconoció que para desarrollar este trabajo se necesitaba una instrucción en la botánica y otros ramos de Historia Natural muy superior a la suya. Sin embargo, entendía que con la experiencia debía "enmudecer el juicio", por lo que debían merecer particular atención las tradiciones populares, como era el caso de las virtudes medicinales que atribuían los indios a las plantas y hierbas que en él se mencionaban.

En su introducción al tomo $X$ del número 414, de 6 de abril de 1806, Bergaño, como editor, hace una profesión de fe. Se considera quizá el único entre los periodistas del universo que escribía "sin otro interés que el del honor", por lo que procuraba sostenerlo con la estimación que había merecido hasta la fecha, aunque en las circunstancias presentes no le era tan fácil como en otros tiempos. Con anterioridad, había sido el único periódico literario de la América septentrional, pero ahora con la aparición del Diario de México, lamentaba que, sintiéndose solo, obligado a tratar de muchas cosas, su labor contrastaba con la de ese periódico en el que intervenían "muchas y buenas plumas". Precisaba que debía contar con los literatos de Guatemala, "picados por el honor de su patria, y por el de ellos mismos". Pero eso no era así porque parecía que "no nacieron con este genio y que también hay literatos egoístas". Esa soledad contribuía a que no satisficiese los gustos de los suscriptores, porque unos demandaban que tratase de agricultura, otros de artes, otros de industria, otros de estudios y "muchos que se hable de noticias inconexas". Él no reunía en sí mismo ese saber enciclopédico, ya que entendía que le faltaba muchísimo para contarse entre los talentos de esa especie, aunque por su amor propio había tratado de imbuirse de él, pese a ser un joven que no tenía otras intenciones que las de "acrisolar su literatura". La guerra en Europa había reducido las dimensiones del periódico, pero ansiaba que la paz y una nueva imprenta volverían a enderezar su curso.

En su número 476, de 15 de abril de 1807, insiste en el plan de su gaceta y trata de justificar por qué había desatendido las noticias políticas. Entendía que se debía a que la mayor parte de los suscriptores eran de Nueva España. Al ser Veracruz el único de la América septentrional al que llegan los navíos desde la Península, era lógicamente el primero en el que se sabían las noticias. Ante esa realidad era absurdo dar a la luz informaciones retardadas que desde ese punto se comunican a los lectores de la Gaceta de México que eran los mismos de la de Guatemala. Sostenía que los acontecimientos políticos en Europa eran materias privativas de la amplia historia " $y$ no de un periódico literario y diminuto que como el de Guatemala, [que] está consagrado a la instrucción pública". Por ello defendía que "los pensamientos nuevos, las invenciones y descubrimientos útiles, todo lo que interesa al comercio, agricultura y artes", así como "los documentos de la buena moral, y las materias que, aunque no precisamente nuevas, sean poco sabidas e interesantes a la comodidad de la vida, como la Economía, etc," eran el campo de actuación de la Gaceta, "mientras la tenga a su 
cargo el Editor que la escribe y publica en el día". No obstante, no se mostraba contrario a la publicación de aquellos acontecimientos que tuviesen relación con el sistema de gobierno, siempre que conviniese darlos a la luz. Al estar próximo a concluirse el tomo IX, expresó que en el $X$ proseguiría con su plan, que consistía en que la convertía no en una obra meramente política, "sino literaria en su mayor parte, y que su objeto, lejos de ser el de referir noticias vagas y de ninguna utilidad, se dirige a propagar la instrucción". En definitiva. que se daría preferencia a una memoria sobre el carbón, "harto más interesante para la humanidad que la relación de las terribles y recientes batallas de Austerlitz, Weimar o Gena". Efectivamente publicó en ese mismo ejemplar "Del carbón y sus aplicaciones", copia de un texto del Semanario de Agricultura madrileño.

Se pondría punto final a la revista en su número de 1 de julio de 1807. Los problemas económicos, los crecientes costes del papel con la contienda bélica, la escasez de suscriptores y los conflictos personales cada vez más agudos con el capitán general Antonio González Sarabia, que conducirían a su fulminante expulsión de Guatemala el 18 de marzo de 1809, abocarían a su cierre. En ese interregno el cántabro trató de abrir una nueva etapa del rotativo, pero se frustró por la falta de apoyo que encontró en la máxima autoridad de la capitanía. Concluyó de esa forma un proyecto singular, protagonizado por el cántabro Simón Bergaño, un autodidacta ilustrado que trató de romper las barreras ideológicas y expandir la revista hacia el ámbito novohispano. A pesar de sus dificultades y de su redacción casi en exclusiva, convirtió al rotativo en un experimento singular de ideas avanzadas en el corazón de Centroamérica. En él, junto con las obligadas noticias políticas, incorpora la literatura, con la publicación de sus versos y la difusión de las novedades literarias procedentes tanto de España como de Nueva España, la educación de la sociedad con planteamientos reformistas que tratan de profundizar en la mejora de las condiciones de vida de las mujeres y de los indios, planteamientos que disgustarían abiertamente a los sectores conservadores, entre ellos el propio prelado de la diócesis. Pero también la difusión de los ideales racionalistas y experimentalistas, plasmadas en su difusión de los viajes científicos, de los saberes científicos. Insiste en que La Gazeta de Guatemala no fuera una revista localista, sino abierta al mundo y conectada con el exterior, pese al aislamiento del territorio. Por ello muchos de sus suscriptores procedían de Nueva España y en ellos trataba de influir en sus escritos y composiciones, incorporando las disciplinas más innovadoras, como acontecía con sus artículos sobre la frenología. Esa concepción abierta y esas ansias de libertad en todas las esferas, incluidas las de su vida personal, fueron finalmente la espita que llevó a la clausura del periódico y poco después a su fulminante destierro. 


\section{Referencias}

Bergaño y Villegas, S. (2008). Poemas. Prólogo de César Brañas. Guatemala: Tipografía Nacional.

Bergaño y Villegas, S. (1812). Pronta vindicación contra el libelo infamatorio impreso contra Simón Bergaño y Villegas. La Habana: Imprenta de Juan de Pablo.

Bertrand, M. (2007). Poder, negocios y familia en Guatemala a principios del siglo XIX. Historia Mexicana, vol. LVI (núm. 3), 863-917.

Chandler, D.S. (1976). Jacobo de Villaurrutia and the Audiencia de Guatemala, 17941804. The Americas, vol.32 n³, 402-407.

García González, A. (2013). Descubridores de la mente. La frenología en Cuba y España en la primera mitad del siglo XIX. Sevilla: CSIC, Universidad de Sevilla, Diputación de Sevilla.

Hernández Pérez, J. S. (2015). La Gaceta de Guatemala, un espacio para la difusión del conocimiento científico. México: Universidad Autónoma Metropolitana y Universidad Autónoma de México.

Lanning, J. T. (1956). The Eighteenth-Century Enlightenment in the University of San Carlos de Guatemala. Ithaca, New York: Cornell University Press.

Luque, E. (1962). La Sociedad Económica de Amigos del País de Guatemala. Sevilla, Escuela de Estudios Hispanoamericanos.

Poupeney Hart, C. (2021). Gaceta de Guatemala in the colonial period. https://doi.org/10.1093/acrefore/9780199366439.013.916. Oxford Research Encyclopedia Latin America History.

\section{Nota biográfica}

Manuel Hernández González es Catedrático de Historia de América de la Universidad de La Laguna. Ha sido profesor invitado y becario postdoctoral de la Universidad de Johns Hopkins de Baltimore y coordinador del Centro de Documentación de Canarias y América del Cabildo de Tenerife. Ha publicado más de sesenta libros, diez de ellos reeditados en América y más de cien artículos, capítulos de libro y ponencias de congresos. Ha editado con estudio crítico y notas más de 20 textos políticos y libros de viajeros. Entre sus obras destacan El Círculo de los Gálvez. Formación, apogeo y ocaso de una elite de poder indiana, Liberalismo, masonería y cuestión nacional en Cuba (1808-1823), Resistencia y adaptación. La pugna del campesinado guajiro isleño del Occidente de Cuba contra la sacarocracia (1670-1817), Los canarios en la Venezuela colonial (1670-1810), El Sur dominicano. Cambio social y transformaciones económicas (1670-1795), entre otras. 